\title{
Improved Learning Management System (i- LMS): A Flat Form for Content Creation and Sharing for Kenyan Secondary Schools
}

\author{
Anthony Mutua Nzioki \\ Jomo Kenyatta University \\ of Agriculture and \\ Technology, \\ School of Computing and \\ Information Technology, \\ P.O. Box 62000 - 00200 ,
}

\author{
Wilson Cheruiyot \\ Jomo Kenyatta University \\ of Agriculture and \\ Technology, \\ School of Computing and \\ Information Technology, \\ P.O. Box 62000 - 00200,
}

\author{
Nicholas Mutua Muthama \\ Taita Taveta University \\ College, \\ School of Sciences and \\ Informatics, \\ P.O. Box 630 - 80300, City, \\ Square, Nairobi, Kenya
}

City Square, Nairobi, Kenya

City Square, Nairobi, Kenya

\begin{abstract}
Use of ICTs integration for enhanced learning has been studied for some time now with focus mainly on content delivery. It has however been noted that ICTs usage for learning has not picked well and in a uniform way. Further, little has been done to ensure delivery from a common pool so as to promote standardization of curriculum delivery especially on content creation and sharing. This has left a gap in ICT usage and improvement of delivery. The main objective in this paper is to look at the usability of learning management system software (LMS) and recommend the development of an improved interactive learning management system (i-LMS) to facilitate data collection from users to support teaching and learning functions in secondary schools. The model shall enable content creation and sharing among students, teachers, content developers and administrators. Captured data will be kept in a common repository in a database for access by all schools for learning. This will help improve delivery through Learning Management Systems software by making it possible to avail resources to a bigger audience from a common pool.
\end{abstract}

Keywords: ICT Integration, i-LMS, Improved Interactive Learning Management System, Enhanced Learning

\section{INTRODUCTION}

Information and Communications

Technologies (ICTs) have been integrated in education in many developing and developed countries alike however the use of ICTs in Kenyan secondary schools lags behind. [13] argue that the use of ICTs in curriculum delivery or eLearning is inevitable and the skills are very necessary to participate in the knowledge societies and economies of the world.

One way of looking at e-learning gives the following approaches
- Enhanced approach which enhances face to face learning using web-based technology e.g. Learning Management Systems (LMSs)

- Blended approach which focuses on both face to face and online learning and

- Online approach which uses online learning only.

Supported by two modes of e-learning

- Asynchronous where learning content is served from a web server and is 
available any time so learners access it at their own pace.

- Synchronous where all learners and facilitator are logged in at the same time and communicate directly and virtually with each other.

Much of the world seems to have adopted enhanced eLearning using the asynchronous mode. On the other hand only a few Kenyan schools boast of a pool of useful resources that can help them deliver in their teaching and learning effectively regardless of which mode is used for delivery and are found mainly in urban areas. Many Kenyan secondary schools lack useful resources like libraries or are poorly equipped where available. Yet schools keep on increasing in numbers every other day against the dwindling number of teachers as well. This means an acute shortage of learning resources in the school settings alongside uneven distribution of resources. Hence there cannot be uniformity in curriculum delivery.

\subsection{General Overview}

Use of ICTs is supported by [8] by saying ICTs have brought a new dawn in curriculum delivery which is no longer optional but a necessity in schools at various levels of learning. [12] gives one example of this revolution as the development of learning management systems (LMS), course management systems (CMS), and virtual learning environments (VLE) that facilitate teaching and learning outside the physical classroom. She further says often, these terms are used interchangeably in designating the same tools or software. The government has shown an effort in the provision of ICTs infrastructure as well as few schools going out to purchase their own computers for use. Although most of them are used primarily for office work or computer literacy classes, this can be overturned by converting them to teaching and learning tools that can be used both online and offline.

[11] in a study to investigate the use of web tools in UK, content that learners are clearly motivated to use Web 2.0 tools for learning and teachers have an important role to play in assisting learners in using these technologies.
This therefore implies that the same learners can give reliable feedback that can be used to help improve what is delivered through the Learning Management Systems as well as sharing which has not been the case. Open source software has enabled the integration of learning modules through the development of Learning Management Systems (LMS) and Content Management Systems which have capacity for forums, instant messaging, and online submission of work and the marking of such work. These systems however are however keen on providing a module for feedback on assignments yet they can be improved to upload user content from schools with resources so as to be accessed by schools without resources for use.

Technology acceptance and usage being an active area of research, has seen several models and theories proposed so as to understand the driving force behind technology adoption [2]. However there has not been a good way to help collect and process data on ICTs usage in the classrooms for purposes of improving delivery with ICTs since available LMSs collect data mainly on user interaction with stored content with no interface for direct user input of created content. Nevertheless LMSs can have a built-in tool that allows create content and store in the learning management system database for later use. By looking at the expected improvement on curriculum delivery by the use of LMSs in secondary schools especially in the rural areas, elearning for secondary schools is given a high priority in this paper.

\subsection{Background}

Most secondary schools are located in rural areas hence are isolated geographically and socially hence face a number of problems in ensuring quality curriculum delivery. Such schools face problems like lack of teachers, inadequate teaching and learning resources as well as poor quality teaching among others. Schools located in remote areas are therefore disadvantaged as far as learning resources are concerned compared to urban areas. The government is working very hard to raise the quality of education and also to expand access yet the scarce resources are limiting this good move. Hence the need to look for an equalizer as 
far as provision of resources and quality curriculum delivery is concerned. It is visualized that once network connectivity is established in secondary schools, sharing of the said learning resources will make teaching and learning enjoyable as well as help realize set goals in curriculum delivery.

It is against this background that content creation and reuse through a shared LMS to enhance learning is recommended. Focus should therefore be on the development of improved Learning Management System (iLMS) software that can allow content creation, storing at a central place, sharing and reuse amongst schools to enhance learning and create uniformity in the content access and delivery.

\section{ICT IN THE CLASSROOM}

The contemporary perspective of ICTs today in the classroom is teaching with, through or incorporating ICTs as it permits enhanced teaching and learning. It is further denoted as a change in pedagogical practice that uses ICT as a resource, [9]. However [7] argues that the huge educational investment has not produced satisfying evidence of ICT adoption and use in teaching and learning. Further on the same, [10] argue that evidence available suggests that the education sector is investing heavily on ICT but its adoption in the education sector lagged behind the business sector which has picked on technology acceptance and use very well. [6] asserts that the experience of projects failing once project funding is over is common and gives rise to some cynicism. [5] further say one of the shortcomings of using only outcomesbased indicators for quality assurance is that they are often not very useful for improving the (often complex) processes that lead to desirable outcomes. It is however possible to improve delivery through updating and sharing of learning resources available through users of the provided technology which has not been the case today. Such learning resources may be delivered through LMSs.

\subsection{Learning Management System (LMS)}

According to [17] an LMS is an integrated software that automates administration tracking and reporting of courses or programmes through the following functions; centralized and automated administration; use of self-service and self-guided services; assembling and delivering learning content rapidly; consolidating training initiatives on a scalable web based platform; supporting portability and standards; and personalizing content and enabling knowledge reuse. [1] [5] assert that a brief search of leading journals on research in higher education and national websites responsible for teaching and learning, such as the Higher Education Academy in Great Britain and Educause in America, offers evidence of the frequency of this type of learning situation. The Open University of the UK for example currently uses an LMS, Moodle, for its users in its distance learning programmes and is rated as the second-largest Moodle deployment by user-base. Despite this widespread use, the aspect of content creation and sharing from the learners for improving the delivery of the LMSs in enhancing learning has not come out well.

The concept of Learning Management Systems (LMSs) in the classrooms has been embraced of late as a sure way of introducing technology in the classrooms. They can be server-based or cloud based software programs that mainly contain information about users, courses and content [16]. According to [15] a Learning Management System (LMS) is a software application for the administration, documentation, tracking, reporting and delivery of e-learning education courses or training programs. Further [3] sees an LMS as a software application or web-based technology used to plan, implement and assess a specific learning process. Several surveys are carried out to investigate the factors that are related to the use of computer technology in teaching and learning processes by teachers [4]. However not much has been done focusing on content creation by the learners.

Nonetheless existing LMSs do not seem to have factored in a module for input of data from the user for improvement of the LMS 
but instead depend on automated captures of user interaction with the systems. Hence data collection and sharing has not fully realized its intended objective of supporting improvement of delivery through the LMS software.

This leaves out a gap that would otherwise have been filled if there was a dependable feedback from the users of the LMSs tailored to collect data that would help assess the usability of the software in question in realizing the intended goals of curriculum delivery as well as add details to stored content for reuse.

This paper therefore focuses on use of LMSs software in the classrooms to create content and upload with an aim to improve delivery through sharing of the same data by schools.

\section{PROPOSED}

\section{METHODOLOGY}

\subsection{Web 2.0 Tools and Learning}

In a research done by [14] there is a host of student and tutor support tools included in the LMS systems. Web 2.0 tools are highly useful in enhanced eLearning for they provide new ways of creating, collaborating, editing and sharing user-generated content online and with ease of use while learning. Tools like blogging, wikis, Googledocs, podcasts, and online photo galleries can be developed and used for the teaching and learning of certain topics in a variety of subject areas. However, the availability and quality of specific tools vary. It was felt there was need for better support and more tools for teamwork and collaboration.

\subsection{The Cloud Concept}

As an evolving paradigm in data management, cloud computing can be an effective tool if used to store learning content in a centralized database for access. It entails the practice of using a network of remote servers hosted on the Internet to store, manage, and process data, rather than a local server or a personal computer. The following framework thus puts into use of the concept of cloud computing in ensuring that teachers and learners from different schools can create, upload and share content in a common platform. This will promote the creation of a resource database for use by all secondary schools as well as uniformity in delivery regardless of distance.

\subsection{The i - LMS Model Application}

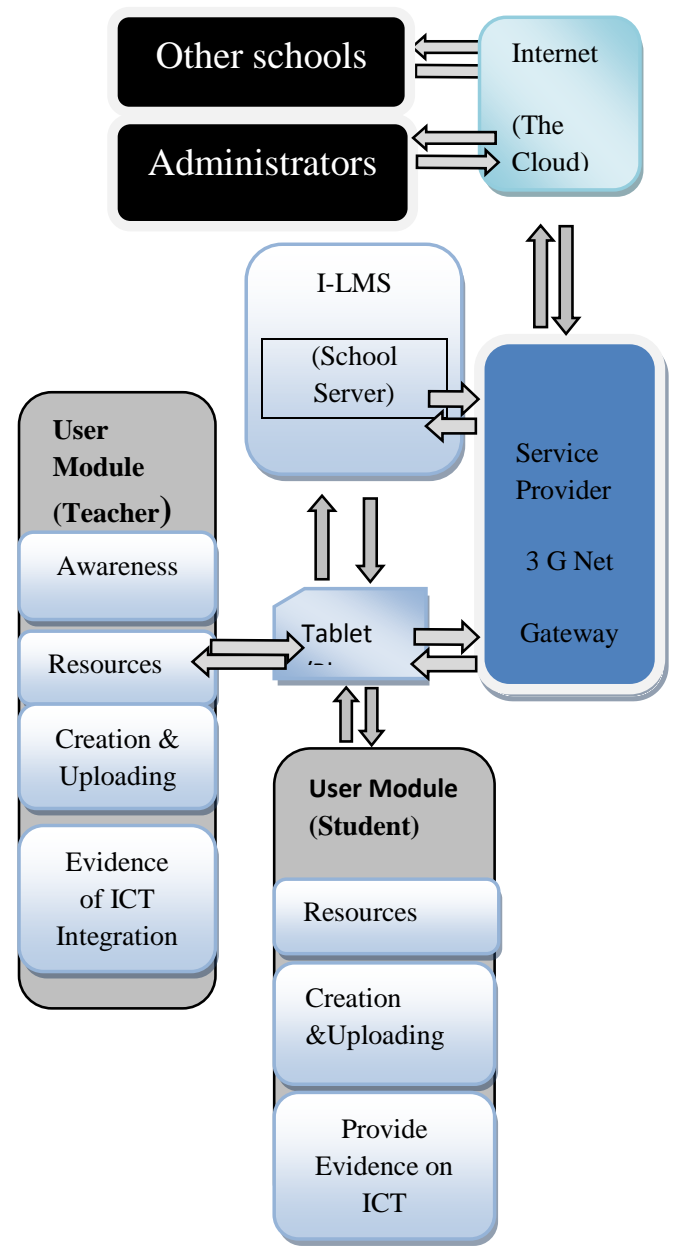

Figure 1: The $\mathrm{i}$ - LMS 
Table 1: The I-LMS Application

\begin{tabular}{|l|l|}
\hline Resources & $\begin{array}{l}\text { Communication programs to } \\
\text { the users in support of ICT } \\
\text { integration in classrooms }\end{array}$ \\
\hline Data Access & $\begin{array}{l}\text { Application will be designed } \\
\text { to use tablets, mobile phones } \\
\text { or computers to access data }\end{array}$ \\
\hline $\begin{array}{l}\text { Content } \\
\text { Creation and } \\
\text { Uploading }\end{array}$ & $\begin{array}{l}\text { A two way communication to } \\
\text { help create and upload content } \\
\text { and evidence of ICT } \\
\text { integration in the classrooms }\end{array}$ \\
\hline $\begin{array}{l}\text { Analysis and } \\
\text { Summaries }\end{array}$ & $\begin{array}{l}\text { Developed application will } \\
\text { provide support for data } \\
\text { analysis and generate required } \\
\text { summaries from databases in } \\
\text { the internet (cloud) using } \\
\text { uploaded data. }\end{array}$ \\
\hline
\end{tabular}

\subsection{Design and Development}

\subsubsection{Tools}

Tools that may be used include, Unified Modeling Language, VB2010, Macromedia studio (Dreamweaver) ASP.NET, PHP, HTML and Xampp server. The proposed tool will be designed using Unified Modeling Language and will allow use of activity diagrams, use case, diagrams and a flowchart. A database will be developed using Xampp and web based application services by PHP and HTML

\subsubsection{Components of the Model}

The tool will be modeled with three different units. The first unit will be the personal computer (PC) side which will be formed of user interface components, the database and the web server components internet gateway will be setup to run on the server and have access to back-end database server for interactive usage of the tool, user interface and internet front end will also be connected to a back-end. The programs expected in the PC are Web server, a gate way server, internet webpage, database and its platform and user interfacing between the PC and the appliance. To ensure security connection to the webpage will be secured through the server certificate and secure socket layer (SSL) algorithm. In addition a login/password based access will be setup to prevent unauthorized access.

\section{CONCLUSION}

The Kenyan government is currently doing a project to equip primary schools with laptops for learning. A similar project to equip secondary schools with ICT equipment has been in place for sometime now though not as aggressive as the new one. One major chalenge however remains in the stardadization of content and delivery using the supplied equipment.

This gap can be effectively addressed the discussed cloud computing model which proposes a module to capture and store data that can be used for reuse by students and teachers at their own convenience from various points. This can become a reality especially with the intended supply of electricity to all areas in the country. As well gadgets that can access internet can be purchased at affordable prices by all interested parties. Thus with a common storage in the discussed cloud concept, learning content can be accessed as from anywhere. Developed content as well will be uploaded for sharing in a common repository. This will thus ensure uniformity in content delivered and ease of accessibility by all regardless of the area on is located.

It is therefore recommended that the Kenyan Government should embrace the use of cloud computing to centralise curriculum delivery from a common pool. This will see the implementation of ICT integration in teaching and learning in schools succeed in delivering and sharing same standard content become a reality.

\section{ACKNOWLEDGEMENT}

Publishing is a requirement in my on-going studies for a masters degree. I would like to acknowledge the good work of moulding me that is being done by $\mathrm{Dr} \mathrm{W}$. Cheruiyot of Jomo Kenyatta University of Agriculture and Technology. 
International Journal of Computer Applications Technology and Research Volume 4- Issue 2, 86 - 91, 2015, ISSN:- 2319-8656

\section{REFERENCES}

[1] Abbas Abdoli Sejzi, B. A. (2013, July 1). Learning Management System (LMS) and Learning Content Management System (LCMS) at Virtual University. 2nd International Seminar on Quality and Affordable Education (ISQAE 2013), pp. 216-220. Retrieved from http://educ.utm.my/tl/wpcontent/uploads/2013/11/301.pdf

[2] Akbar, F. (2013, October 21). What affects students acceptance and use of technology? Retrieved from Dietrich College Honors Theses.: http://repository.cmd.edu/hsshonors/17 9

[3] Aziah, N., \& Marzuki, W. (2005). Innovation for Better Teaching and Learning: Adopting the Learning Management System. Malaysian Online Journal of Instructional Technology, 2(2), pp. 2740.

[4] Baek, Y., Jong, J., \& Kim, B. (2008). What makes teachers use of technology in theclassroom? Exploring the factors affecting facilitation of technology with a Korean sample. Computers and Education, Vvol.50, no. 8, pp. 224234.

[5] Ellis, R. A., \& Calvo, R. A. ( 2007 ). Minimum Indicators to Assure Quality of LMS-supported Blended Learning. Educational Technology \& Society, , Vol 10 (2), 60-70.

[6] Farrell, G. (2013, October 15). ICT in Education in Kenya - infoDev. Retrieved from infoDev:www.infodev.org/en/Docume nt.409.pdf

[7] Gülbahar, Y. (2007). Technology planning: A roadmap to successful technology integration inschools. Computers \& Education, Vvol. 49, no. 4, pp. 943956.

[8] Kaur, R., \& Sidhu, G. K. (2010). Learner autonomy via Asynchronous Online Interactions: A Malaysian Perspective. International Journal of Education and Development using Information and
Communication Technology, Vol. 6, Issue 3, pp. 88-100.

[9] Law, N., Pelgrum, W. J., \& Plomp, T. ((eds) 2008). Pedagogy and ICT Use in Schools around the World - Findings from the IEA SITES 2006 Study. Hong Kong: Springer.

[10] Leidner, D., \& Jarvenpaa, S. L. (1995). The use of Information Technology to enhancemanagement school education. A theoretical view. MIS Quarterly, pp. 265-291.

[11] Luckin, R., Wilma, C., Graber, R., Kit, L., Mee, A., \& Oliver, M. (2009). Do Web 2.0 really open the door to learning? Practices, perceptions and profiles of 11-16 year olds. Learning, Media and Technology, Vol (34) 2 87-104.

[12] Martin, F. (2008). Blackboard as the Learning Management System of a Computer Literacy Course. MERLOT Journal of Online Learning and Teaching, Vol. 4, No. 2.

[13] Oye, N. D., A.Iahad, N., \& Ab.Rahim, N. (2012). Using Mixed method Approachto Understand Acceptance and Usage of ICT in Nigerian Public University. International Journal of Computers \& Technology, Volume 2 No. 3.

[14] Paulsen, M. F. (2003). Experiences with Learning Management Systems in 113 European Institutions. Educational Technology \& Society, 6 (4) 134-148.

[15] Ryann, E. K. (2009, 20-06-2013 20). Field Guide to Learning Management Systems. ASTD Learning Circuits.

[16] Sharma, A., \& Vatta, S. (2013). Role of Learning Management Systems in Education. International Journal of Advanced Research in Computer Science and Software Engineering, Vol 3, 6 pg 997-1002.

[17] Suman, N., Chawan, P., \& Meshram, B. B. (2011). CMS, LMS and LCMS for elearning. International Journal of Computer Science Issues, Vol 8, Issue 2,644 . 